\title{
Patient and public perspectives shaping scientific and medical research: panels for data, discussions, and decisions
}

This article was published in the following Dove Press journal:

Patient Intelligence

13 January 2012

Number of times this article has been viewed

\section{Seilin Uhm' \\ Kristin Liabo' \\ Ruth Stewart ${ }^{1,2}$ \\ Rebecca Rees' \\ Sandy Oliver'}

'Social Science Research Unit, Institute of Education, University of London, London, UK; ${ }^{2}$ The Centre for Language and Culture, University of Johannesburg, Johannesburg, South Africa
Correspondence: Sandy Oliver Social Science Research Unit, Institute of Education, University of London, 20 Bedford Way, London WCIH ONR, UK Tel +442076I2 6747

Fax +442076126400

Email s.oliver@ioe.ac.uk

\begin{abstract}
This paper explores the role of patient panels for shaping research for health, scientific research about health and illness, and applied medical research. After examining the history and purposes of involving patients in discussions and decision making for research, it outlines the expertise and skills required if panels are to be successful. The paper also analyses existing guidance for panels that include patients. Panels benefit from the experiential knowledge of panel members, craft knowledge of panel facilitators, and organizational knowledge gained through previous experience of hosting panels. Guidance is available that addresses structures and resources (for panel funders) and interpersonal communication and group dynamics (for panel members and facilitators). This guidance is most comprehensive when it has itself been developed by all these types of stakeholders.
\end{abstract}

Keywords: public involvement, patient panels, expert panels, guidelines, guidance

\section{Introduction}

The broad definition of a "panel" is a "small group of people brought together to investigate or decide upon a particular matter."' Of central importance to such panels are the different kinds of people who work together and the expertise that they bring to inform discussion or decisions. Increasingly, panels advancing scientific knowledge about health and illness, and about medical research for treatments, are acknowledging the different kinds of expertise that usefully complement the experience and skills of researchers. Patients and their carers are experts in their own experience of health. Clinicians and other professionals can bring vital expertise that stems from their experience of practice; product developers and manufacturers likewise.

In scientific and medical research, the term "panel" is used in various ways. The term "expert panel" is often used when people are brought together to discuss or decide what scientific or medical research should be done, and how. Another kind of panel exists where there is a less-explicit reference to expertise. Panels of potential customers, whether patients or clinicians, are long-established elements of market research within the pharmaceutical industry, similar to the customer "panels" in the commercial sector generally (for instance, for media and entertainment, panels of readers, listeners, or viewers). The purpose of market research panels is to collect and analyze information about people's preferences and purchasing power and engage customers actively in reflecting on and discussing their interests and concerns. A second meaning is found in observational research where "panel data" refers to information collected from the same individuals, or from individuals in the same locations, over time with little or no reflection or debate by those being studied. 
These different types of panels constitute a spectrum of potential approaches to expertise, from panel members merely providing data at one end of the spectrum, through investigating and debating matters, to making decisions at the other end. How panels are constructed and what is asked of them depends on their specific purpose.

This paper explores all of the above issues, focusing in particular on the role that can be played by panels that include patients and wider publics. It identifies the opportunities within research projects, programs and governance systems for patients and other experts to bring their expertise to bear and the different reasons for this involvement. Using findings from a systematic review of public participation in agenda setting in research, it then examines the history of public panels, identifying both commercial and public sector origins. Panels are then distinguished in terms of their precise purpose: eliciting data, facilitating discussion, and sharing decisions. After considering the different kinds of knowledge, skills, and expertise that can be mobilized for panels, the paper reviews existing guidance on setting up and running patient panels, identifying differences in their emphasis and detail, and how this relates to the types of knowledge harnessed for their design.

\section{Expert panels within science and medicine}

Figure 1 illustrates a range of opportunities within England for experts to exert an influence before research is undertaken, while it is being undertaken, and after it is completed.

Each of these opportunities for experts to influence what or how research is conducted or used is an opportunity for patients to exert an influence too. As shown in the bottom row of Figure 1, research teams designing individual studies may reach out to other people with experience that complements their own, including experience of illness or of using health services or products, even at the stage of preparing funding applications. Indeed, some research programmers make this a requirement of funding in addition to the requirement for

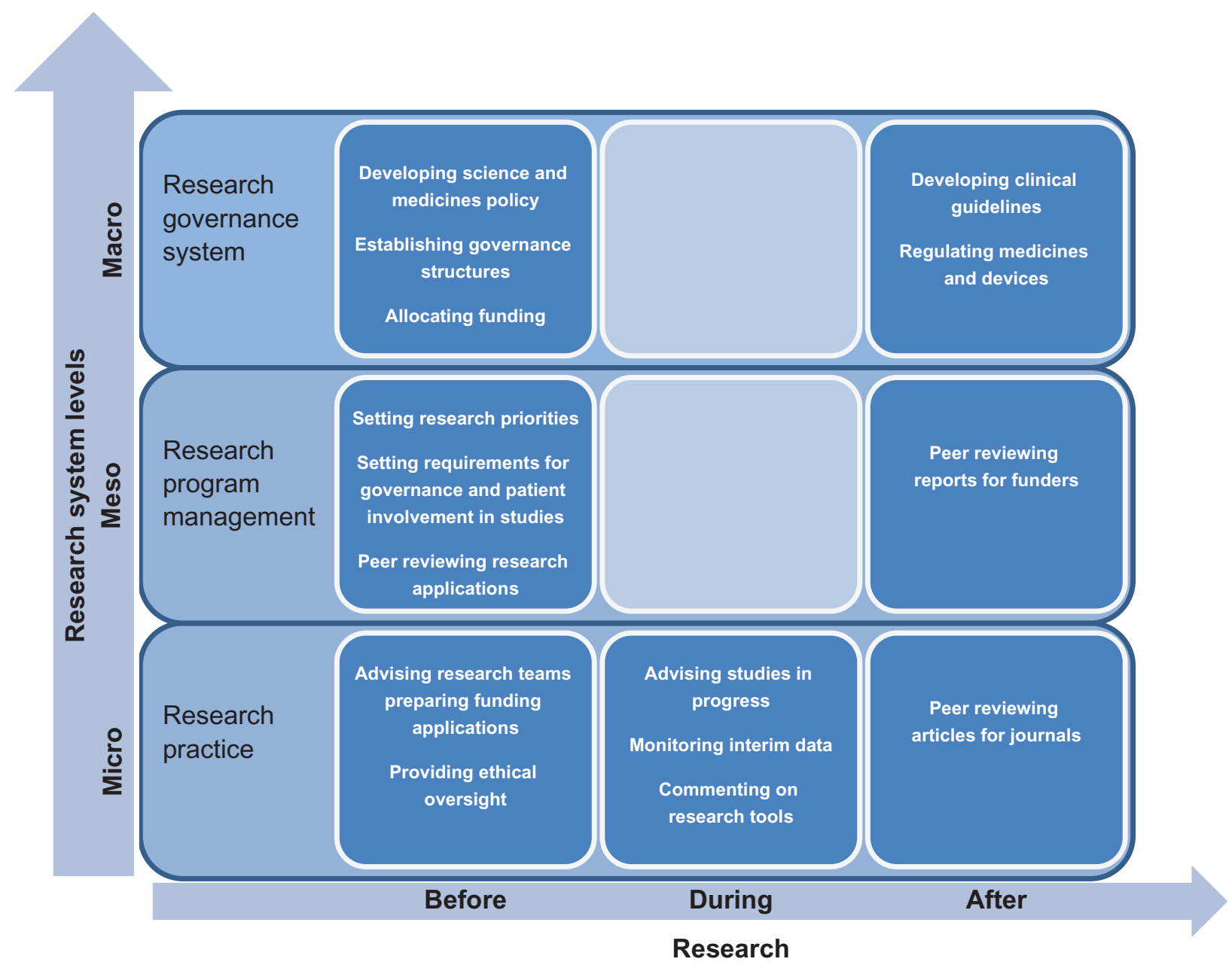

Figure I Expert input into research systems, management, and practice. 
seeking approval from a research ethics committee, which also includes patient or public members. ${ }^{2}$ Once underway, studies may be guided by advisory groups that include patients, or patients may comment on data-collection methods and tools. Data monitoring committees that inspect interim data are essential to many trials but less likely to have patient members. Once complete, articles submitted to journals are peer reviewed, sometimes by patients. ${ }^{3}$

The middle row of Figure 1 represents funded studies that are conducted within research programs relying heavily on expert panels to decide what research to commission and to judge the worth of studies proposed by researchers. Research programs may involve patients in these processes and set standards for patient involvement in individual studies. Like journals, funders maintain panels of experts for peer reviewing research reports and these experts are sometimes patients. For instance, in England, the National Institute for Health Research (NIHR) Health Technology Assessment program includes patients in all these procedures. ${ }^{4}$

In turn, research programs work within national and international structures for research governance (top row of Figure 1). Whether considering the conduct of science or its use for public services, research policy is developed largely by politicians who, in a representative democracy, speak for the patients. In England they convene panels of members of parliament, known as select committees, and invite witnesses to give evidence, including contributions from researchers and patients as external experts. ${ }^{5}$ Science policy is then implemented through universities to which the Higher Education Funding Council for England distributes public funds for research according to expert panels' assessment of research excellence. These panels include members from the private, public, or third sectors with considerable expertise in commissioning, applying, or making use of research. ${ }^{6}$ When it comes to using research findings, expert panels are also convened to develop policies to determine the use of medicines, devices, or clinical practices more widely. Patient involvement in panels for developing guidelines is not only widespread but also a widely accepted quality standard. ${ }^{7}$

The two empty cells in Figure 1 indicate the principle of independence in the conduct of science: although funders or policy makers may choose the research questions, it is not their place to influence the answers. Nevertheless, funders monitor the progress of studies they support. The Alzheimer's Society even draws on its own panel of carers to conduct monitoring visits to ensure accountability to the funders (who in this case rely heavily on charitable giving from patients' families and wills) ${ }^{8}$; involving carers reminds the researchers of the ultimate purpose and meaning of their work for people with Alzheimer's disease and their families.

\section{Why bring patients to expert panels?}

Evidence-informed health services seek findings from research that employs methods to minimize bias and error, but this is of limited benefit if no thought is given to possible bias and misunderstandings inherent in the research questions. Drawing on their experience of health problems and health care provision, patients' commentaries on research have focused on the choice of interventions attracting research attention and the choice of outcomes used to evaluate them. Cancer patients considered research about the management of practical, social, and emotional issues as a higher priority than investigating the biology or treatment of cancer. ${ }^{9}$ Similarly, people suffering from osteoarthritis have called for more research about patient education when the research literature predominantly addresses oral drugs. ${ }^{10}$ Critiques have repeatedly noted: a lack of functional, social, and emotional outcomes; a lack of long-term outcomes (which require more effort to follow patients for a longer period of time); reliance on scales (often ratios or combinations of measures) that offer a quantitative assessment of effect that cannot be translated into a meaningful assessment of health; and little assessment of adverse reactions (often rare, so these only appear in large observational studies rather than small- or medium-sized trials). ${ }^{11,12}$ Policy makers who need to decide where to focus resources, when offered evidence of the effects of intervention, often also want to know not only whether something works but also whether it is better or worse than the alternatives and at what cost. Practitioners with responsibility for delivering complex interventions want to know not only what works but also how it works and what is needed to set it up. Finally, what is to be done in the absence of reliable evidence of effectiveness? Policy makers need to choose policies, practitioners have to set up and deliver interventions, and patients have to choose treatments, whether or not the research tells them what they want to know. Thus, judgments are made when deciding what research is to be done and how, and when using the findings. This raises questions about who the research belongs to. Who can judge appropriately what research is done - the people who do the research or the people well placed to use the findings?

There are two key arguments for involving a broad range of people in making judgments about doing and using research. ${ }^{13}$ First, as democracy expands from representative democracy alone to include participatory democracy, 
involvement is increasingly "politically mandated" for people to have a say in decisions which affect them; this principle is supported by ethical arguments and enshrined in human rights. Second, involvement leads to better, more relevant decisions, helping to win support for change and facilitating the uptake of services. These arguments have led to the current situation where decisions about research are often made by researchers working together with people bringing other expertise.

\section{Commercial origins of patient panels}

When seeking examples internationally of patients or publics influencing research agendas, the earliest and most detailed examples were found in the commercial sector where they were convened to support the commercial development of devices to help disabled people lead more independent lives. ${ }^{14}$ A market research model that involved potential customers brought the "voice of the consumer" to every stage of development, engineering, and production and used oneto-one interviews with customers to elicit experiences, with the reflection and creativity provided by multiple analysts reading interview transcripts. Although 20-30 interviews were required to identify $90 \%-95 \%$ of customer needs (and thus the research and development priorities), this may have been more cost-effective than focus groups with similar participants. $^{15}$

Other commercial enterprises working in the same area raised the analytical power of the customers' contributions either by their choice of customers or by developing questions to prompt more thoughtful customer responses. A Delphi study relied upon a hand-picked group of analytical and articulate long-term users of assistive devices with a variety of disabilities to provide "valuable insight into the evaluation factors used by one group of disabled persons whose members have given careful thought to how assistive devices should be designed, manufactured and selected."16 A similar consumer-responsive development process identified research and development priorities by involving power wheelchair users in brainstorming and five rounds of voting. ${ }^{17}$ An alternative model for raising the analytical powers of product users was to invest more effort into the development of probing questions to ask focus groups. ${ }^{18,19}$ Questions were developed by teams that typically included experts in the product (an engineer and a knowledgeable end user), the commercial context (a marketer) and research methods (the focus group facilitator and an expert in qualitative data analysis). Together they drew on personal experience, engineering standards, consumer reports, academic research, market research, and industry and consumer interviews to write the questions. This effort led to three types of product requirements: (1) those that were assumed, often unspoken as they were too obvious to mention; (2) those that were important day-to-day concerns; and (3) those that were exciting opportunities that could give a product a leading edge in the market place. Focus groups were followed by wider surveys to assess the importance of each requirement before deciding the direction of the research and development.

The enthusiasm amongst the research and development teams for hearing the "voice" of their customers was clear. ${ }^{15}$ It gave them a "greater awareness of users' feelings and perceptions." ${ }^{17}$ Although portrayed very positively in these reports of engineering research, the authors of this study have not found such creative partnerships reported by the large commercial sector of the pharmaceutical industry the reasons may be technical, commercial, or ethical. First, the intellectual gap between the social and biological aspects of medicines may be particularly challenging to bridge. Second, where pharmaceutical companies do bridge this gap, they may not wish to reveal a commercial advantage. Last, it may be because pharmaceutical companies are discouraged from approaching patients directly or attract criticism when they partner patient organizations. Pharmaceutical industry funding of patient groups raises doubts about their independence and reliability as patient advocates. ${ }^{20}$ Others argue that funding from pharmaceutical companies enables organizations to speak for patients more effectively whilst defending their independence. ${ }^{21}$ Despite these difficulties, market research with patients and clinicians is widespread on pharmaceutical company websites that encourage patient dialog and may well, as one site intends, accelerate real-world medical research. ${ }^{22}$

\section{Public sector origins of patient panels}

A consumer model for engaging patients transferred to the public sector in the 1980s when many countries privatized state services and adopted market terminologies and management systems to those that remained in public ownership. ${ }^{23}$ This was supported by the Organization for Economic Co-operation and Development, which promoted a form of performance management in the public sector. For instance, market research and consumer satisfaction surveys were encouraged in the National Health Service $(\mathrm{NHS})^{27}$ and the Citizen's Charter portrayed users of public services as customers with rights and choices through which they could influence the quality of the services they are offered. ${ }^{24,25}$ 
Although public sector involvement shares some of the same methods employed in the commercial sector (for instance, focus groups and interviews in the public sector revealing "what mattered to patients deeply influenced researchers' thinking"), ${ }^{26}$ patients actively involved in influencing research frequently came from organizations that originated as part of the health advocacy movement of the 1970s and 1980s. In England, this included growing numbers of patient panels attached to general practices and the National Association for Patient Participation was founded in 1978; it continues to "promote the role of Patient Participation Groups as participants in decision making within the NHS."27

As more explicit evidence-informed decision making for health care evolved in the 1980s, patient advocacy and campaigning groups focused their attention not only on health services, but also on the relevant (or in their eyes, sometimes, irrelevant) research conducted for health care. ${ }^{28}$ Patient involvement in deciding what research is done - setting research agendas - is now widespread. By the new millennium, policy documents reported involvement in setting agendas on a national and an international scale. ${ }^{14} \mathrm{At}$ that time, patient or public panels were employed in Delphi surveys to set research priorities for peer review of research funding applications and at consensus conferences. Far more common than patient or public panels, however, was patient or public membership of panels that also included clinicians and researchers, with patients or members of the public being a small minority. This was the model adopted for agendasetting panels for NHS research and development starting in the late 1990s. At that time there were very few formal studies of patients involved in prioritizing research, ${ }^{14}$ but a decade later a systematic review identified 27 formal studies. ${ }^{29}$ Patients are also involved in decisions about funding research teams, either "peer" reviewing research applications or sharing the decisions as members of a funding panel. ${ }^{2}$

\section{Purpose of panels: data, discussions, or decisions}

Panels can be used to elicit patients' ideas, facilitate patients' discussion, and for decision making. Where people offer their own ideas alone, the theory of statistical sampling requires larger numbers to paint an unbiased picture of the wider population. Public opinion polls have long been used to gather opinions on biotechnology. ${ }^{30,31}$ Large numbers can also be accommodated by standing panels where members offer responses to a series of consultations, an arrangement employed by the Alzheimer's Society when seeking carer views on research proposals. ${ }^{8}$ Smaller numbers are common when people speak for others, for instance, as respondents to public consultations or members of advisory groups being familiar with current debates through their affiliation with patient organizations. Without careful distinction of the different meanings of "representation," these different approaches are sometimes confused. Large numbers of people may be chosen to present an image (represent) of a larger population, whereas small numbers of people are chosen with the knowledge and skills to (re)present the opinions of a wider group.

An ethnographic study of a panel of citizens, set in the context of the wider research literature, identified factors that support or challenge deliberation. ${ }^{25}$ Panels are not just for sharing fully formed ideas; rather, their value is in providing a "space" that is "legitimate" and "safe" in which people can share and develop their collective expertise. Whilst science is based on rational argument and scientists often consider emotional engagement with debates about science inappropriate, clear strong positions can polarize and clarify by engaging emotion as well as intellect. Engagement with a developing argument may be enhanced by strong opposing views expressed either by panel members or facilitators. Emotion and anecdote can be the "motivation to discuss, and to engage with, material and with fellow citizens." ${ }^{25}$ The Citizens' Council encountered two barriers to engaging with arguments or developing collective expertise related to the principle of fairness. Formal procedures to ensure "fair" participation (speaking in order of request) and tacit rules (such as asking only one question each) sought the ideal of answering everyone's questions rather than the goal of exploring issues in depth. The "unfairness" inherent in health inequalities prompted discomfort, conflict, and evasion as panel members struggled to discuss principles of social justice and cultural respect without implicating personal relationships and individual blame. ${ }^{25}$ Discussing sensitive topics with others requires particular skills for participants and facilitators.

A third purpose of panels is to make decisions. These panels are rarely comprised entirely of patients. It is far more common for patients to belong to panels with mixed membership; for instance, ethics committees, agenda setting panels, commissioning boards, or guideline development groups. The challenges encountered by the Citizens' Council above are compounded when patients or members of the public deliberate with clinicians and researchers. This requires respect for different types of knowledge, relevant expertise and the skills to share that expertise, and willingness to learn from others. 


\section{Knowledge, expertise, and skills}

People with different perspectives and experience bring different types of knowledge. These have been characterized as: organizational knowledge that is gained by the experience of organizing services (eg, knowledge about governance and regulation); practitioner knowledge that is gained by the experience of professional practice (ie, practice skills); service user knowledge, gained from experience of and reflection upon services or situations; and policy knowledge, gained from the wider policy context. ${ }^{32}$

Bringing together in expert panels people with such different types of knowledge raises questions about the meaning of "expert." Traditionally, theories about expertise have valued specialists whose knowledge is recognized by their qualifications or affiliation to a professional body: the "certified experts." ${ }^{33}$ Experts may also be recognized for their specific skills or competencies or their ability to clearly frame and solve problems. ${ }^{34}$ Expertise that lies primarily in informal knowledge, derived from practice, participation, or experience in a particular field has been described as "experience-based expertise." ${ }^{33}$ Experience-based experts have traditionally been excluded from knowledge sharing and decision making because their knowledge has been seen as inferior to certified expertise.

Observations of multidisciplinary working suggest that people who only acknowledge the model of expertise that values their own experience may be less open to ideas offered by people who are experts according to other models. People with a broad attitude to expertise who acknowledge the value in all the models discussed find it easier to see the value of others' contributions and to work in multidisciplinary environments. ${ }^{35}$

These different attitudes to expertise were apparent from the framing of public consultations about bioethics. ${ }^{36}$ Some consultations were mounted with the aim of identifying "gaps in their knowledge and understanding in order to devise public education programs to remedy the deficits"; the researcher was the expert, applying structured methods focused on objective, measurable aspects of the topic and separating facts from values. Other consultations aimed to "uncover what the public knows and thinks about scientific developments and applications" in which the researcher was involved in the subject of study as a learner in order to produce new insights and understanding, employed open methods to elicit rich responses, and acknowledged that "facts" vary with context.

Discussions about expertise relate to the extent to which someone is valid as an expert in a given field. The UK organization INVOLVE refers to "non-researchers" as "members of the public," which means that practically everyone can be an expert. Collins and Evans are far more specific in recognizing the boundaries of expertise within a given field. ${ }^{33}$ They argue that in the past "scientists were often attributed with authority to speak on subjects outside their narrow areas of specialization." ${ }^{33}$ Instead, they argue, expertise is carried in the person of the contributor and, as such, certified and experience-based experts alike need to have in-depth knowledge of the topic to which they are contributing. This means that a dietician is not necessarily an expert on food policy, and a "member of the public" does not necessarily have the expertise to sit on a patients' panel.

Considering scientists and nonscientists as having "pockets" of expert knowledge that they can contribute to science and other people as having expertise in interactional or facilitation skills has implications for whom to involve in decisions about science and public sector research. To consider which problems most deserve research, individuals must know something of a range of problems and understand the purpose of research. If a panel is convened for the purpose of discussion, they also need the skills to engage with these issues and discuss them with other people. Involving patients or the public makes this an exercise in participatory democracy. To improve research or the use of research, individuals need some expert understanding about specific problems and to understand the nature, potential, limitations, and options for research as well as the skills to engage with these issues and discuss them with other people. This is a collaborative activity of experts where each member of a panel brings their own background knowledge and skills for discussing research. Their engagement with the issues may be enhanced by increasing their knowledge before and during panel discussions with background papers and presentations. Their discussions may be enhanced by the use of facilitators who bring strong interactional skills for bridging their different professional and personal worlds. Bringing these different worlds together is not merely an instrumental exercise requiring some translation between different languages or spheres of expertise, but it can lead to emotional and dramatic group dynamics, an aspect of engagement that is rarely addressed in evaluations ${ }^{37}$ and is more easily accommodated with the help of a skilled independent facilitator.

\section{Guidance for panels and involvement}

Social research methodology provides sufficient guidance for panels where the purpose is to collect and analyze data from panel participants. ${ }^{38}$ Conventional committee procedures with agendas, speaking through the chair, voting, and minutes also have a history stretching back 1000 years through parliaments 
and other democratic institutions. ${ }^{39-41}$ However, neither of these approaches adequately supports discussions and decisions about research by or with patients and the public. Panels convened to discuss or make decisions about research need additional guidance that acknowledges the combination of technical and interpersonal elements of this work.

Tables 1 and 2 list a purposive sample of sources of advice for involving patients and the public in decisions about research and using the findings; these sources of advice vary in terms of their scope (being applicable to specific health conditions or health generally) and are all relevant to England as exercises that were national, European, or worldwide. Inspection of these sources of guidance revealed variations in their development: the extent to which the guidance is based on experiential knowledge, practice knowledge, organizational knowledge, and research knowledge; and whether consensus about the guidance was achieved formally or informally (Table 3).

Analyzing this range of advice according to the type of knowledge it rests on reveals three clusters of documents (see Figure 2). One cluster consists of guidance that focuses on systematized knowledge; on methods for identifying evidence for clinical guidelines, ${ }^{7}$ for comparing burden of disease with lack of research, ${ }^{42}$ or for appraising descriptions of public involvement in research. ${ }^{43}$ All three tend to focus on structures, resources and procedures. Because the purpose of the Appraisal of Guidelines for Research and Evaluation $\mathrm{II}^{7}$ instrument is to appraise the quality of guidelines, only one of its six domains addresses "stakeholder involvement." This domain considers whether professional stakeholders were panel members and whether the views and preferences of the target population (patients, public, etc) were sought; but neither question considers how well people were involved or their views or preferences sought. The World Health Organization methodology for setting research priorities includes a guiding principle of inclusivity to ensure as wide a participation as

Table I Application of advice for involving (and evaluating) patient membership of panels

\begin{tabular}{lll}
\hline & Doing research & $\begin{array}{l}\text { Using } \\
\text { research }\end{array}$ \\
\hline $\begin{array}{l}\text { Involving patients } \\
\text { in panels }\end{array}$ & $\begin{array}{l}\text { INVOLVE }^{45} \\
\text { Telford et al }^{48} \\
\text { Cartwright and Crowe }\end{array}$ & $\begin{array}{l}\text { EURR }^{49} \\
\text { Cartwright et al }^{44} \\
\text { The James Lind Alliance }\end{array}$ \\
& $\begin{array}{l}\text { World Health Organization } \\
\text { A2 }\end{array}$ & \\
Assessing patient & Wright et al & \\
involvement & Telford et al & \\
\hline
\end{tabular}

Note: *Appraisal of Guidelines for Research and Evaluation (AGREE) II was for assessing the quality of the process and reporting of clinical guideline development. Abbreviation: EULAR, European League Against Rheumatism.
Table 2 Context for developing advice for involving (and evaluating) patient membership of panels

\begin{tabular}{|c|c|c|}
\hline & National & International \\
\hline Health condition specific & Wright et al (cancer) $)^{43}$ & EULAR (arthritis) ${ }^{49}$ \\
\hline \multirow[t]{4}{*}{ Generic health } & INVOLVE $^{45}$ & AGREE $\|^{7}$ \\
\hline & Cartwright and Crowe ${ }^{44}$ & World Health \\
\hline & The James Lind Alliance ${ }^{47}$ & Organization ${ }^{42}$ \\
\hline & Telford et $\mathrm{al}^{48}$ & \\
\hline
\end{tabular}

Abbreviations: AGREE, Appraisal of Guidelines for Research and Evaluation; EULAR, European League Against Rheumatism.

possible and stakeholder deliberation to allow for "equitable voice, constructive debate and conflict resolution" but offers little detail about how this can happen. ${ }^{42}$ Although Wright et al had access to tacit knowledge through their experience of patient involvement as well as formalized knowledge, little tacit knowledge seems to have been retained during the development of an instrument for critically appraising reports of patient or public involvement; the focus is more on structures and procedures than interpersonal communication. ${ }^{43}$

Another cluster rests on tacit knowledge, the experiential and practice knowledge or craft skills gained through direct experience of patient and public involvement. ${ }^{44,45}$ These are concerned less with the structure of panels and more with the procedures (such as the need for good information and training), practicalities, and interpersonal dynamics including respect for patient knowledge. INVOLVE guidance asserts the need for contributions to be respected, and includes a person specification for public members that emphasizes clear communication and a receptive attitude ${ }^{45} \mathrm{~A}$ tool kit provides advice from two facilitators familiar with the research about involvement based on their many years' experience of patient and public involvement in health and research. ${ }^{44}$ This includes practical advice about seating arrangements, eye contact, language, tone, body language, active listening, nonverbal communication, and teleconference etiquette.

Between these two clusters is guidance based on both tacit knowledge and formalized knowledge. Development of the European League Against Rheumatism (EULAR) strategy began with a systematic review of active patient participation in research, followed by researchers, clinicians and patients familiar with collaborative working employing a Delphi method to agree eight recommendations for patient involvement. ${ }^{46}$ Although most of the eight EULAR recommendations focus on structures and procedures for patient involvement, two focus on interpersonal communication: on the "communication skills, motivation and constructive assertiveness" of the patient research partners and on the responsibilities of the principal investigator to "facilitate and encourage the contribution of patient research partners, 


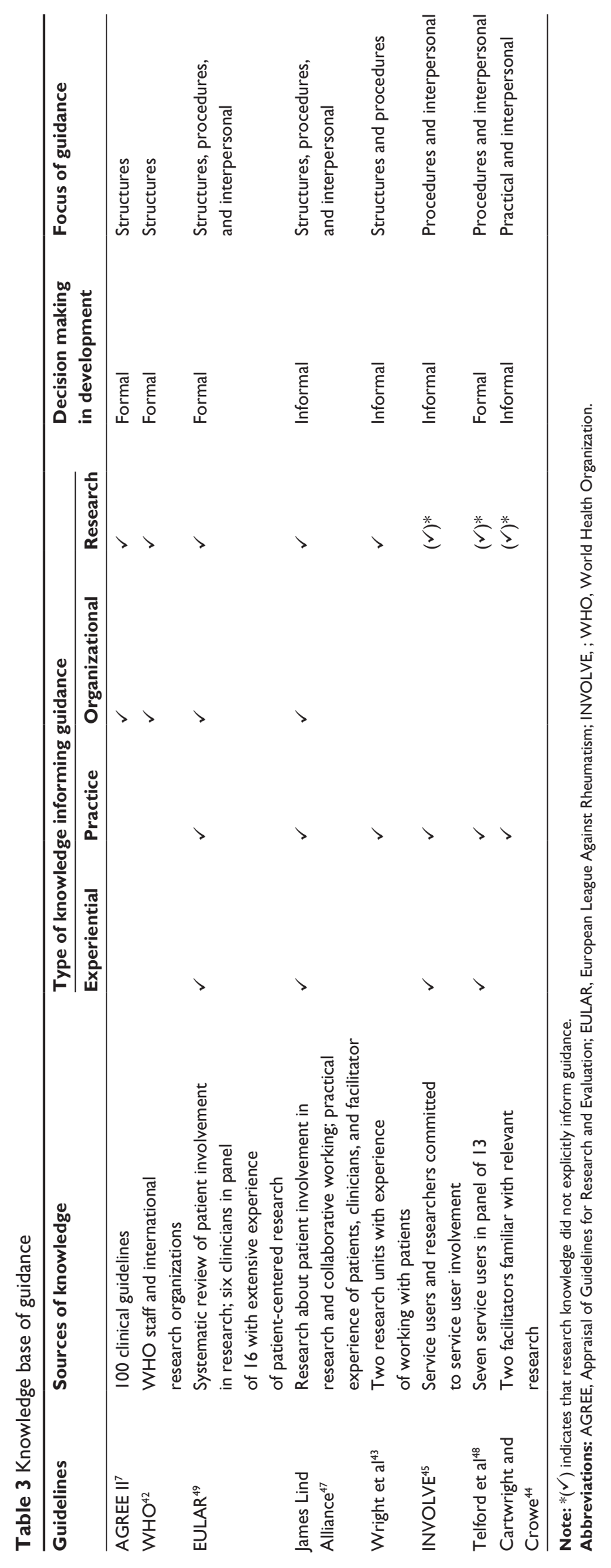




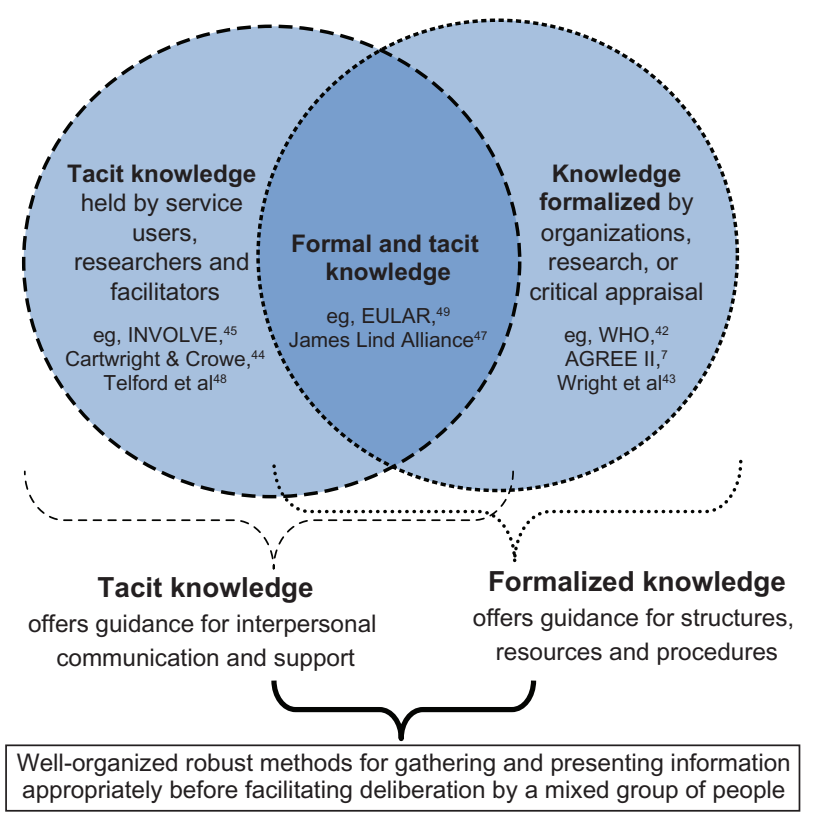

Figure 2 Types of knowledge underpinning guidance for panels, including patients and publics.

and consider their specific needs." These recommendations for patient involvement are complemented by the EULAR standardized operating procedures that offer additional points about presenting research information to panels. ${ }^{46}$ The James Lind Alliance Guidebook ${ }^{47}$ also draws on research knowledge about patient involvement in research and collaborative working, and on the practical experience of patients, clinicians, and facilitator. It similarly offers guidance on structures, procedures (including presenting research information to panels), and interpersonal communication; for the latter, it emphasizes how to manage different values and perspectives.

\section{Conclusion}

As part of the advocacy movement, patient and public panels for science and medicine have evolved from customer panels or population panels into expert panels that benefit from the reflective powers of patients who bring valuable direct experience of giving and receiving care. Panels with all-patient or public membership provide a forum for valuable debate but are distanced from the decision-making forum. Panels with a mix of patients or public and researchers risk marginalizing patient members who attend the forum, either because of their structures (minimum patient numbers) or because patient members lack support for working in an alien culture.

Comprehensive guidance that addresses structures and resources (for panel funders), processes (for panel hosts), and interpersonal communication and group dynamics (for panel members and facilitators) is available where panel members and panel facilitators have been involved in developing the guidance. Such guidance draws on the experiential knowledge of panel members, craft knowledge of panel facilitators, and organizational knowledge accrued from hosting panels. Where the development or application of quality criteria are mediated by written reports (eg, critical appraisal guidelines or a systematic review), the focus is on structures and organizational procedures. As with the evaluation of public involvement, ${ }^{25,37}$ guidance for patient (membership of) scientific and medical panels is comprehensive only when it acknowledges the emotional and interpersonal aspects of collaborative working, as well as the intellectual, procedural, and structural.

\section{Acknowledgments}

Seilin Uhm was supported by the NIHR as part of a program grant on "Improving quality of care at very preterm birth." Kristin Liabo was funded by the NIHR research training fellowship programme.

\section{Disclosure}

Sandy Oliver's contribution was informed by working with the NIHR Health Technology Assessment Program and The James Lind Alliance. The views expressed in this review are those of the authors and not necessarily those of the NHS, the NIHR or the Department of Health. The authors report no other conflicts of interest in this work.

\section{References}

1. Simpson JA, Weiner ES, Oxford University Press. The Oxford English Dictionary. 2nd ed. Oxford: Clarendon Press; 1989.

2. Staley K, Hanley B. Scoping Research Priority Setting (and the Presence of PPI in Priority Setting) with UK Clinical Research Organisations and Funders. Oxford: James Lind Alliance; 2009. Available from: http://www.twocanassociates.co.uk/perch/resources/files/TwoCan\%20 JLA\%20report\%20March\%2009_with\%20appendices.pdf. Accessed November 18, 2011.

3. Lapsley P, Godlee F. Involving patients in the BMJ. BMJ. 2007; 334(7608): 1334.

4. Royle J, Oliver S. Consumer involvement in the health technology assessment program. Int J Technol Assess Health Care. 2004;20(4):493-497.

5. Department of Chamber and Committee Services. Guide for select committee members. 2011; Available from: http://www.parliament. uk/documents/commons-committees/guide-select-ctte-members.pdf. Accessed November 18, 2011.

6. Research Excellence Framework 2014. Assessment Framework and Guidance on Submissions. Bristol: Higher Education Funding Council for England; 2011.

7. Brouwers MC, Kho ME, Browman GP, et al. AGREE II: advancing guideline development, reporting and evaluation in health care. CMAJ. 2010;182(18):E839-E842.

8. Alzheimer's Society. Involving people with dementia and their carers in research [web page on the Internet]. London: Alzheimer's Society; 2011. Available from: http://www.alzheimers.org.uk/site/scripts/documents_info.php?documentID=1109. Accessed October 1, 2011.

9. Corner J, Wright D, Hopkinson J, Gunaratnam Y, McDonald JW, Foster $\mathrm{C}$. The research priorities of patients attending UK cancer treatment centres: findings from a modified nominal group study. Br J Cancer. 2007;96(6):875-881. 
10. Tallon D, Chard J, Dieppe P. Exploring the priorities of patients with osteoarthritis of the knee. Arthritis Care Res. 2000;13(5):312-319.

11. Oliver S. Exploring lay perspectives on questions of effectiveness. In: Chalmers I, Maynard A, editors. Non-random Reflections on Health Services Research. London: BMJ Publishing Group; 1997:272-291.

12. Oliver S. Users of health services: following their agenda. In: Hood S, Mayall B, Oliver S, editors. Critical Issues in Social Research: Power and Prejudice. Buckingham: Open University Press; 1999:139-153.

13. Entwistle VA, Renfrew MJ, Yearley S, Forrester J, Lamont T. Lay perspectives: advantages for health research. BMJ. 1998;316(7129):463-466.

14. Oliver S, Clarke-Jones L, Rees R, et al. Involving consumers in research and development agenda setting for the NHS: developing an evidencebased approach. Health Technol Assess. 2004;8(15):1-148, III-IV.

15. Griffin A, Hauser JR. The voice of the customer. Marketing Science. 1993;12(1):1-27.

16. Batavia AI, Hammer GS. Toward the development of consumer-based criteria for the evaluation of assistive devices. J Rehabil Res Dev. 1990;27(4):425-436.

17. Brienza D, Angelo J, Henry K. Consumer participation in identifying research and development priorities for power wheelchair input devices and controllers. Assist Technol. 1995;7(1):55-62.

18. Lane JP, Usiak DJ, Stone VI, Scherer MJ. The voice of the customer: consumers define the ideal battery charger. Assist Technol. 1997;9(2):130-139.

19. Stone VI, Bauer SM, Lane JP, Usiak DJ, Khan Z, Prabhu C. Wheelchair tie-downs: ideal features and existing products. Technol Disabil. 1998;8(3):159-178.

20. Mintzes B. Should patient groups accept money from drug companies? No. BMJ. May 5, 2007;334(7600):935.

21. Kent A. Should patient groups accept money from drug companies? Yes. BMJ. 2007;334(7600):934.

22. PatientsLikeMe. The Value of Openess [blog on the Internet]. Cambridge, MA: PatientsLikeMe; 2011. Available from: http://blog.patientslikeme. com/category/drug-safety/. Accessed November 18, 2011.

23. Boote J, Telford R, Cooper C. Consumer involvement in health research: a review and research agenda. Health Policy. 2002;61(2):213-236.

24. Barnes M. Public Expectations: From Paternalism to Partnerships; Changing Relationships in Health and Health Services. Policy Futures for UK Health series. London: The Nuffield Trust; 1999.

25. Dent M. Citizens at the centre: deliberative participation in healthcare decisions - by Davies, C., Wetherell, M. and Barnett, E. Sociol Health Illn. 2007;29(5):787-788.

26. Wennberg JE, Barry MJ, Fowler FJ, Mulley A. Outcomes research, PORTs, and health care reform. Ann N Y Acad Sci. 1993;703:52-62.

27. National Association for Patient Participation (NAPP). More and Better Patient Participation [homepage on the Internet]. Walton on Thames: NAPP; 2011. Available from: http://www.napp.org.uk/. Accessed November 18, 2011.

28. Stocking B. Implementing the findings of Effective Care in Pregnancy and Childbirth in the United Kingdom. Milbank Q. 1993;71(3): 497-521.

29. Stewart RJ, Caird J, Oliver K, Oliver S. Patients' and clinicians' research priorities. Health Expect. 2011;14(4):439-448.
30. European Commission. Europeans and biotechnology: EUROBAROMETER 46.1. Brussels: European Commission; 1997.

31. Macer DR. Perception of risks and benefits of in vitro fertilization, genetic engineering and biotechnology. Social Sci Med. 1994;38(1):23-33.

32. Pawson R, Boaz A, Grayson L, Long A, Barnes C. Types and Quality of Knowledge in Social Care. Knowledge Review 3. London: Social Care Institute for Excellence; 2003.

33. Collins HM, Evans R. The third wave of science studies. Soc Stud Sci. 2002;32(2):235-296.

34. Blackmore P. Mapping professional expertise: old tensions revisited. Teacher Development. 1999;3(1):19-38.

35. Stewart R. Expertise and Multi-disciplinary Training for Evidenceinformed Decision Making. London: Institute of Education, University of London; 2007.

36. Levitt M. Public consultation in bioethics. What's the point of asking the public when they have neither scientific nor ethical expertise? Health Care Anal. 2003;11(1):15-25.

37. Harvey M. Drama, talk, and emotion: omitted aspects of public participation. Sci Technol Human Values. 2009;34(2):139-161.

38. McNeill P, Chapman S. Research Methods. Abingdon: Routledge; 2005.

39. Althingi Administration. Althingi. Reykjavík: Althingi Administration; 2010. Available from: http://www.althingi.is/pdf/Althingi2010_english. pdf. Accessed November 5, 2011

40. Malcolm J, editor. Erskine May: Parliamentary Practice. 24th ed. London: LexisNexis Butterworths; 2011.

41. Roberts H, Honemann D, Balch T, Seabold D, Gerber S. Robert's Rules of Order Newly Revised. 11th ed. Cambridge, MA: Da Capo Press; 2011.

42. World Health Organization (WHO). Priority Setting Methodologies in Health Research. April 10-11, 2008. Geneva: WHO; 2008.

43. Wright D, Foster C, Amir Z, Elliott J, Wilson R. Critical appraisal guidelines for assessing the quality and impact of user involvement in research. Health Expect. 2010;13(4):359-368.

44. Cartwright J, Crowe S. Patient and Public Involvement Toolkit. Oxford: Wiley-Blackwell; 2011.

45. Hanley B, Bradburn J, Barnes M, et al. Involving the Public in NHS, Public Health and Social Care Research: Briefing Notes for Researchers. 2nd ed. Eastleigh: INVOLVE; 2003. Available from: http://www.invo.org.uk/pdfs/ Briefing\%20Note\%20final.dat.pdf. Accessed November 18, 2011.

46. Dougados M, Betteridge N, Burmester GR, et al. EULAR standardised operating procedures for the elaboration, evaluation, dissemination, and implementation of recommendations endorsed by the EULAR standing committees. Ann Rheum Dis. 2004;63(9):1172-1176.

47. Cowan K, Oliver S. The James Lind Alliance Guidebook. Version 3. Oxford: James Lind Alliance; 2011. Available from: http://www.jlaguidebook.org/pdfguidebook/guidebook.pdf. Accessed November 8, 2011.

48. Telford R, Boote JD, Cooper CL. What does it mean to involve consumers successfully in NHS research? A consensus study. Health Expect. 2004;7(3):209-220.

49. de Wit MP, Berlo SE, Aanerud GJ, et al. European League Against Rheumatism recommendations for the inclusion of patient representatives in scientific projects. Ann Rheum Dis. 2011;70(5):722-726.
Patient Intelligence

\section{Publish your work in this journal}

Patient Intelligence is an international, peer-reviewed, open access journal that characterizes and measures the central role of patient behavior and intention in optimizing healthcare management in all areas of disease and complaint types. An improved understanding of patient intelligence coupled with predictive analysis helps an organization contribute more effectively to achieving better outcomes. Submit your manuscript here: http://www.dovepress.com/patient-intelligence-journal

\section{Dovepress}

The journal is characterized by the rapid reporting of reviews, original research, methodologies, analytics, modeling, clinical studies and patient surveys across all disease areas. The manuscript management system is completely online and includes a very quick and fair peer-review system. Visit http://www.dovepress.com/ testimonials.php to read real quotes from published authors. 